\title{
Management Model on Electronic Commerce Data Based on Cloud Computing
}

\author{
Hailan Pan $\mathbb{D}^{1,2}$ and Xiaohuan Yang ${ }^{3}$ \\ ${ }^{1}$ Research Center of Resource Recycling Science and Engineering, Shanghai Polytechnic University, Shanghai 201209, China \\ ${ }^{2}$ School of Economics and Management, Shanghai Polytechnic University, Shanghai 201209, China \\ ${ }^{3}$ Cosco Shipping Technology Co., Ltd., Shanghai, China
}

Correspondence should be addressed to Hailan Pan; panhailan@sspu.edu.cn

Received 5 February 2021; Revised 8 March 2021; Accepted 1 April 2021; Published 16 April 2021

Academic Editor: Wenqing Wu

Copyright (C) 2021 Hailan Pan and Xiaohuan Yang. This is an open access article distributed under the Creative Commons Attribution License, which permits unrestricted use, distribution, and reproduction in any medium, provided the original work is properly cited.

\begin{abstract}
Judging from the current situation, China's e-commerce companies are developing more and more rapidly, and the sales records of e-commerce platforms continue to break through. However, in this rapid development, many problems have been exposed. Because B2C e-commerce business management methods are different from traditional business management methods, there are many fundamental differences between the risks faced by traditional e-commerce companies and traditional enterprises. Compared with traditional enterprises, the risks faced by e-commerce enterprises have greater uncertainty and complexity, and the related risk management measures have not fully kept up with the development speed of B2C e-commerce and are still in the stage of continuous exploration. With the popularity of e-commerce and higher applicability, the research on e-commerce data management model is urgent. In order to study the e-commerce data management model, theoretical research and commercial application of cloud computing are discussed in depth from literature analysis, comparative analysis, graphical analysis, and case analysis. I hope to expand the application research of cloud computing platform in e-commerce. Finally, it proves that e-commerce has a good development advantage in the future development.
\end{abstract}

\section{Introduction}

With the advancement of the times, the application, popularization, and development of Internet technology, as one of the most basic activities of human activities, has undergone tremendous changes. On the one hand, because online shopping is not limited by time and space, it does not require faceto-face communication and communication between buyers and sellers, so that consumers can purchase goods without leaving home, and the transaction method is relatively free; on the other hand, due to online shopping, the product categories are diverse and the types are relatively complete. The price is also quite advantageous compared to offline stores. Therefore, more and more consumers are attracted to online shopping, and e-commerce is born. E-commerce has now entered people's lives and infiltrated into people's lives. Therefore, in every big environment where B2C ecommerce [1-3] enterprises want to stand out from the fierce market competition, the quality of enterprise risk management will undoubtedly become a direct factor affecting the competitiveness of enterprises, affecting the survival and development of enterprises. How to strengthen the risk management of $\mathrm{B} 2 \mathrm{C}$ e-commerce enterprises has become a very practical issue.

It can be seen from the introduction of the research background that China's e-commerce has great development potential and good development prospects. From the perspective of long-term development, traditional enterprises are bound to develop into e-commerce enterprises or combine with e-commerce enterprises. Although the competition in the industry is very cruel, only a small number of companies can stand out from the competition and succeed. However, the rapid development of the industry and the rapid changes in the environment have caused many risks and opportunities for enterprises. Whether it is a large-scale enterprise or a small family-owned enterprise, there are plans 
to enter the industry more or less. Therefore, conducting risk management research on the mainstream $\mathrm{B} 2 \mathrm{C}$ model in ecommerce is not only conducive to the development of existing enterprises. Its entry is conducive to the future development of the enterprise and provides valuable experience for it, thereby reducing the risk of new entrants.

On December 18, 2015, General Secretary Xi Jinping said at the second "World Internet Conference - Wuzhen Summit" to accelerate the construction of Internet infrastructure and increase research and innovation and interoperability of network technology and application development. Sichuan has also increased its time and funding investment in other areas of data such as the Internet of Things, big data and cloud computing. This will lower the digital divide and reduce the imbalance of information flow. If it develops well, it may spread network technology in third world countries. As a new business model in today's society, e-commerce is changing the development of the world in its unique way and integrating into people's daily life. With the development of e-commerce, it can be divided into many different modes according to different transaction objects, mainly including B2B [4], B2C, C2C [5], and O20.

Business-to-business (B2B model) is the first ecommerce model to emerge. This model is mainly used for business activities between merchants and businessmen. Through this model, merchants can improve business activity efficiency and reduce costs through network resource management, collaborative work, and information sharing. China's Alibaba, trade network, and other companies are typical B2B models. Business-to-customer (B2C model) is a business-to-consumer model in which business and consumer teams conduct business activities directly. The $\mathrm{C} 2 \mathrm{C}$ model (customer-to-customer) is a consumer-to-consumer model in which consumers use the network for business activities. Consumers promote products they plan to sell on specific e-commerce platforms. Consumers in need can obtain product information through the platform. After the two parties reach an agreement, the transaction is completed. The role of network mediation can be clearly seen from the C2C model. The $\mathrm{O} 2 \mathrm{O}$ mode (online-to-offline) is an online transaction offline consumption experience mode. This model is to use the advantages of the smooth flow of the Internet to launch their own characteristics and create their own brand, and after completing online transactions with consumers, consumers can personally come to the offline experience center to experience and then carry out a real experience.

E-commerce is a new way of trading that is different from traditional business activities. First, on the trading platform, there is no fixed sales location and sales time for ecommerce. E-commerce can provide services according to the needs of consumers, regardless of time and space, and can improve transaction efficiency. Second, through e-commerce, transaction costs can be saved very well, and the cost savings will benefit consumers, and consumers are more willing to choose a network to form a virtuous circle. The ecommerce platform can display products to consumers more comprehensively from the aspects of use, application scope, functional structure, material technology, etc., so that con- sumers can choose a more reasonable purchase method. Third, compared with traditional commerce, e-commerce reduces the intermediate links, allowing direct transactions between producers and consumers, while strengthening communication between producers and consumers, and gradually forming a close cooperative relationship. Based on the advantages of e-commerce, in order to study the ecommerce data management model, the theoretical research and commercial application of cloud computing are discussed in depth from literature analysis, comparative analysis, graphical analysis, and case analysis. I hope to expand the application research of cloud computing platform in ecommerce. Finally, it proves that e-commerce has a good development advantage in the future development.

\section{Cloud Computing and E-Commerce}

2.1. Cloud Computing Overview. Cloud computing [6, 7], the core of which, is to implement distributed computing methods through the network. This technology allows centralized management of shared hardware and software resources as well as informational materials and provides them to computers and other devices as needed. Cloud computing is a distributed computing technology. The most basic concept is to automatically split a large computational processor into a myriad of smaller subroutines over a network and then transfer it to a large system of multiple servers. After searching, calculating, and analyzing, the processing results are returned to the user.

In fact, many of the everyday applications used today are based on cloud computing technology, for example, the commonly used Baidu search engine, 163 network mailbox, and so on. The large-scale distributed computing technology studied by early technologists can be called the origin of "cloud computing." Cloud computing connects distributed technologies to the network and scales to provide more services. The basic principles of cloud computing can be similar. This is like switching from the old single-generator mode to the centralized power supply mode of the plant. This means that computing power can also be circulated as commodities, just like natural gas and hydropower. Again, it is easy to use, low cost, and of course, the biggest difference is that it is transmitted over the Internet. In fact, the cloud of cloud computing represents the entire Internet. Instead of using the software originally installed on your computer, or replacing the original operation of storing data on your own hard disk, you will use the network. This kind of work, and storing the files on the network, is a huge virtual space. We use web services to store data in servers on the network, browse the pages of these services through a browser, and perform various calculations and work using the above interface.

Cloud computing has had a profound impact on the entire IT industry, including three cloud computing builders, server vendors, software developers and cloud terminal providers, and cloud providers as cloud operators. The frame diagram is shown in Figure 1.

Currently, cloud computing includes the following levels of services: infrastructure as a service (IaaS), 


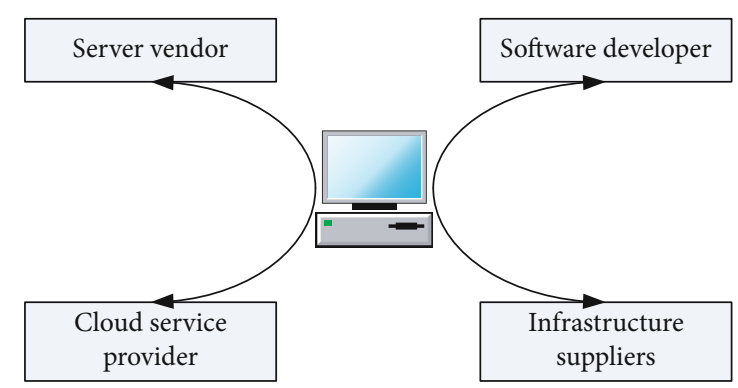

Figure 1: Cloud computing area network.

platform as a service (PaaS), and software as a service (SaaS). The three-tier service architecture is shown in Figure 2.

In terms of services, the main focus is on providing users with a variety of cloud-based services. There are three levels: one is software as a service, called SaaS. The role of this layer is to provide the web to customers. The second is the platform as a service platform service called PaaS. The role of this layer is to provide users with application development and deployment platform as a service: the third layer is the infrastructure as a service infrastructure. The service is abbreviated as IaaS and is used to provide users with various basic computing (such as virtual machines) and storage resources as services. From the user's point of view, the relationship between these three layers of services is independent and different, because the services they provide are completely different and the users are different. But, from a technical point of view, the relationship between the three layers of cloud services is not independent but has a certain dependence. For example, the SaaS layer of products and services not only need to use the technology of the SaaS layer itself but also rely on it. The development and deployment platform provided by the PaaS layer is directly deployed on the computing resources provided by the IaaS layer, and the products and services of the PaaS layer may also be established on the IaaS layer service.

2.2. Advantages and Characteristics of E-Commerce. E-commerce has unparalleled advantages compared with traditional enterprise management, which is mainly reflected in the six aspects shown in Table 1.

(1) Establish corporate image and brand

In the market competition, the company's good image will directly affect its survival. In the traditional business model, it takes a long time to get a good corporate image or product brand name. The business model of e-commerce can obtain corporate image and brand in a relatively short period of time

(2) Shorten the production cycle

E-commerce uses the Internet to synchronize product production information and customer demand information, expand the scope of corporate electronic contacts, share product specifications and drawings, or work with other companies to shorten product life cycles. E-commerce enables suppliers and customers to connect and establish business contacts over the Internet, reducing the time between sending and receiving orders, invoices, and delivery notifications between suppliers and customers

(3) Create new sales opportunities

Because the e-commerce sales model allows products to be sold ( 24 hours a day, 7 days a week), in some ways, the company has found new markets that can attract more customers

(4) Change the internal structure of the enterprise

E-commerce reduces the cost of communication between vertical organizational structures through the Internet. Companies must adapt to this change and restructure to increase efficiency. Therefore, Internet-based e-commerce is changing the internal structure of the enterprise

\section{(5) Changing the way companies compete}

E-commerce provides businesses and consumers with more opportunities to explore consumer markets and consumer choices. At the same time, it also provides a smoother and faster place for information exchange, thus improving the company's macrounderstanding of market demand and consumer understanding. The ability to market information also speeds up the company's ability to develop new products and deliver new services. E-commerce enables companies to quickly understand consumer demand information and quickly feed it back to the decision-making level, making it easier for companies to conduct R\&D activities that target consumer needs. E-commerce has changed the cost structure between the upstream and downstream companies and established strategic alliances between the upstream and downstream companies. E-commerce extends the competition among enterprises to the competition of the entire supply chain, enabling enterprises to compete from the competition of enterprises to the virtual alliance formed among enterprises in various fields such as advertising competition, promotion means, product design, and packaging, mainly reflected in the significant increase in the initial cost of the new company entering the competitive market

\section{(6) Change the basis of enterprise competition}

E-commerce has changed the foundation of corporate competition. On this basis, e-commerce has changed the transaction costs of buyers and sellers. E-commerce can make enterprises with large annual transaction volume relatively smaller than transactions, and enterprises with insufficient financial resources are more profitable and have competitive advantages, because e-commerce has the characteristics of high one-time input cost and low variable cost.

The characteristics of e-commerce can be summarized as follows: 


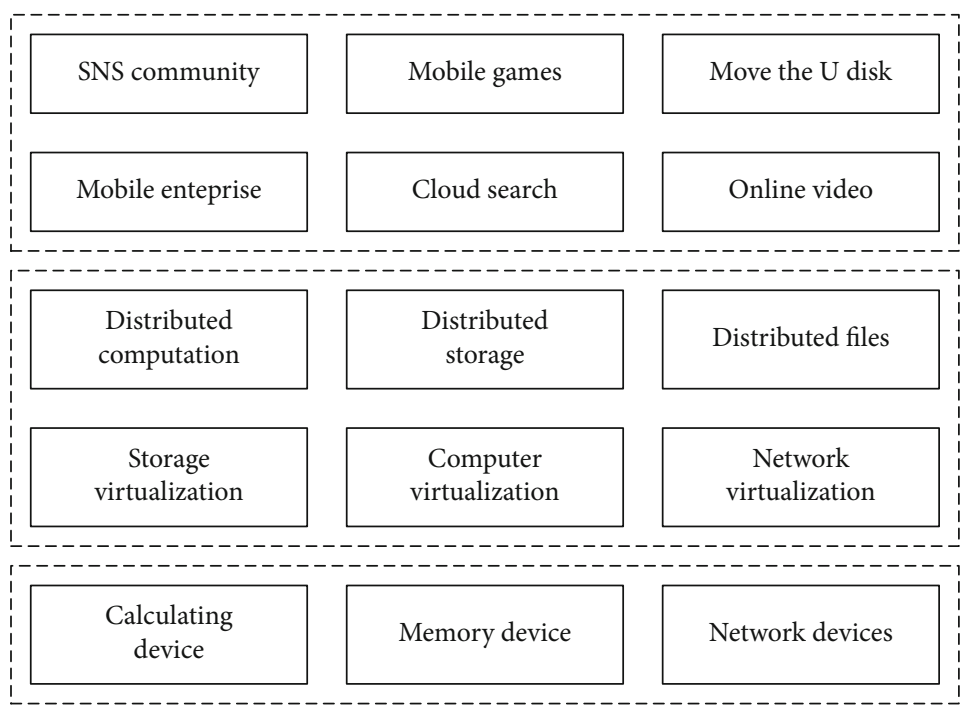

FIGURE 2: Three-tier service architecture diagram.

TABLE 1: Characteristics of e-commerce.

\begin{tabular}{lc}
\hline & Basic characteristics \\
\hline 1 & Establish corporate image and brand \\
3 & Shorten the production cycle \\
4 & Create new sales opportunities \\
5 & Change the internal structure of the enterprise \\
6 & Change the way companies compete \\
\hline
\end{tabular}

(1) Business: this is the most basic feature of e-commerce, namely, the services, means, and opportunities for buying and selling transactions. It is based on the Internet and provides a powerful and comprehensive trading and feedback platform for suppliers, sellers, and customers. It expands the market, increases the number of customers, and provides convenient service to every customer in the supply chain. Therefore, e-commerce is an opportunity for any large enterprise

(2) Serviceability: in an e-commerce environment, customers are not subject to geographical conditions. The focus of buying goods is no longer just low prices. Today's customers also regard service quality as one of the considerations. Therefore, in a sense, service quality has become a key point of business activities, and one of the characteristics of services is convenience. Not only the customer benefits but also the company benefits

(3) Integration: the real business value of e-commerce is to coordinate old and new technologies, enabling users to more effectively use their existing resources and technologies to accomplish tasks more efficiently. The integration of e-commerce lies in the integrity and uniformity of transaction processing. It standardizes the workflow of transaction processing and integrates manual operations and electronic information processing into an inseparable whole. This not only improves the utilization of manpower and material resources but also improves the rigor of the system operation

(4) Coordination: business activities are a process of coordinating business cooperation among customers, manufacturing, suppliers, and business partners. Efficiency is generally based on an interactive protocol as the basis for e-commerce activities

(5) Low cost: e-commerce has obvious low cost

(6) Security: for customers, if there is any doubt about the security of electronic transactions, they will not buy or sell on the Internet at all, and the transactions between enterprises will be the same. Therefore, the security of e-commerce is one of the core issues that must be considered

(7) Electronification and its scalability: one is electronic writing and data transmission of e-commerce; the other is that payment methods are highly electronic. In order for e-commerce to function properly for a long time, it must be ensured that it is scalable because the scalable system is a stable system

Analysis of the seven-point characteristics of ecommerce helps to understand the impact of ecommerce environment on supply chain management. To implement the e-commerce strategy, we must face the coordination of various production factors inside and outside the enterprise, face the market, emphasize customer service and management, pay attention to the integration of various systems, and establish a sound and effective information management system, enabling them to more effectively accomplish their business management goals. 
E-commerce does not completely replace the traditional business model, because traditional businesses also have the advantages that e-commerce does not have. Traditional business allows consumers to experience goods first and then buy them after they are satisfied. Many consumers are more inclined to accept actual goods and enjoy shopping. However, fast and efficient e-commerce is unmatched by traditional companies. With the development of e-commerce, more complex trading methods in traditional businesses will also be optimized, and some traditional businesses may undergo subversive changes. The future will be an era of traditional business and e-commerce convergence. By summarizing, it is found that there is a big difference between traditional business and e-commerce. Therefore, the ecommerce background discussed in this paper is still very different from the previous traditional business background and has certain research value.

\section{Key Technology of Data Management Based on Cloud Computing}

As one of the core functions of cloud computing, cloud storage has received extensive attention. Metadata management plays a key role in cloud storage. Wikipedia introduces metadata in detail: metadata, also known as metadata, and mediation data, is data describing data (data about data), mainly information describing data attributes, such as storage location, historical data, resource search, and file recording. Metadata primarily describes data about file system structures, such as heterogeneous namespaces, file and directory attributes, and file-to-block mappings. Although the size of the metadata is relatively small throughout the file system, operations on metadata account for more than $75 \%$ of the overall file system operation. Therefore, the management of metadata is critical to the performance of the file system.

Today's large-scale cloud computing systems typically have thousands to tens of thousands of node devices, and the CPU cores are numerous. As system processing power and user demands continue to increase, the demand for high-performance distributed file systems is also increasing. According to the statistics of 13 file systems, the files and directories in each file system are hundreds of millions. In addition, the I/O of each CPU core is independent, which results in a large amount of parallel access to the file system. Therefore, the file system in the cloud computing environment needs to process thousands and tens of thousands of operations for metadata every second. This situation shows that it is unrealistic to rely on a centralized server for metadata processing. Only a set of servers can be used for distributed processing of metadata to meet actual needs.

Since the cloud computing system is in the same LAN in most cases, it is very rare that the message is tampered with. Even if the message is incomplete due to the hardware and network of the system, it only needs to be verified by simple verification. The complete message is fine. Therefore, it can be assumed that the cloud computing system does not have a Byzantine general problem. Based on HDFS, this paper proposes a distributed metadata management mechanism in a new cloud computing environment, which provides good scalability and usability for the system while improving metadata operation performance. The metadata mentioned in this article contains catalog metadata as well as file metadata. Directory metadata includes hierarchical namespaces and directory attributes; file metadata includes file attributes and file-to-block mappings.

GLOBLE_ID is a unique global identifier that cannot be changed after the path is created. USER_ID is the identifier of the user who created the path. PARENT_GLOBAL_ID represents the GLOBLE_ID of the path's parent directory. BLOCK_PTR is a pointer to a data block of the file, which is used only for files. Other information such as permissions, last access time, and update time are saved in OTHER META. Through this metadata format, the structured name space is changed to a flat data structure and can be stored in the database and name nodes. Figure 3 shows the architecture of the metadata management system.

The system consists of four main parts: the client, multiple name nodes, name node manager, and database. The system exposes the metadata access interface to the client. To improve system performance, some of the most recently used metadata can be cached on the client. The name node is responsible for managing the metadata and processing metadata access requests from the client. The updated metadata in the name node is periodically persisted to the database. The name node manager provides routing for the client to obtain the target name node. In addition, it manages the distribution of metadata between many name nodes and load balancing by periodically receiving heartbeat signals from name nodes.

\section{E-Commerce Data Management Model}

The logical model of e-commerce data [8-10] is a division of e-commerce data from the user's perspective. It classifies the various information involved in the entire e-commerce and divides the different levels of utilization according to the method of network information organization. According to this model, we can make a good division of the data types of the entire e-commerce according to functions and expressions. From the perspective of network information organization, network information is divided into three levels: micro, meso, and macro.

The mesoorganizational model of network information resources is related to the micromodel, which includes the secondary organization of network information resources and three organizations. Secondary information organization is the reorganization of information organized by various microorganizational models. These three information organizations are the reorganization of secondary information. Online secondary information resource organization mode was used. This mode is very common, including the search engine methods we usually use, the directory guide method (topic tree mode), and the database method. Then, there are three organizations; the reorganization of the secondary information organization, to help users find the right search engine, directory guide, or instruction database faster. This is the organization and management mode of the three information resources of "directory and directory" which represents a search engine directory in multiple search engines. 


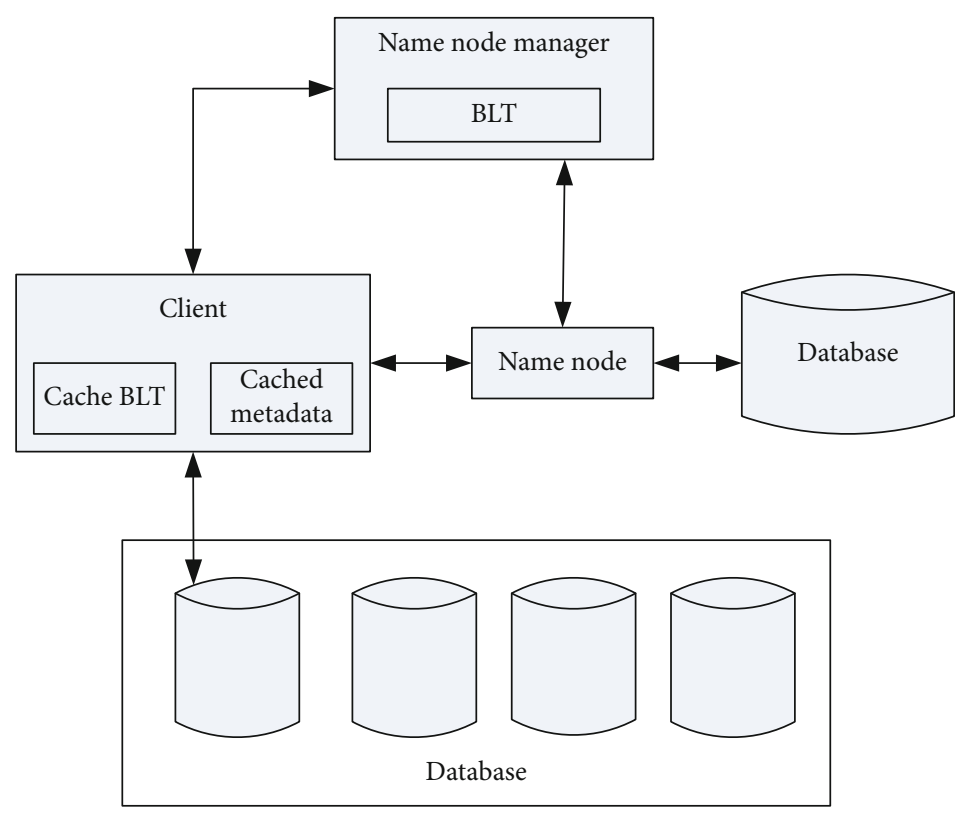

FIgURE 3: Metadata management system architecture.

The model proposed in this paper adopts a multilevel structure, using front-end page cache squid [11], multiple web servers, page fragment cache, Hadoop storage system, DAL data interface layer, memcache distributed cache, and sublibrary strategy. It is roughly divided into four layers, as shown in Figure 4.

After the user's access request is submitted, the front-end page cache is first reached. If the webpage data cached here cannot satisfy the user's request, the Squid server will submit the user request information to the web server. The web server we use here is Apache, which is widely used based on open source servers. The web server then accesses the page fragment cache ESI to see if there is a user request, and if not, what type of user's request is being resolved. If the unstructured data request such as a web page is read, the request is sent to the Hadoop system; if the user logs in, the structured data request such as the user information needs to be viewed, and the request is sent to the database. Then, the two parts get a result and return it to the user.

\section{Performance Analysis}

5.1. The Cost Advantage of E-Commerce under Cloud Computing. Cloud services pay for users based on their needs and also get users based on their own needs. In this way, there is no risk, which can save the cost of the e-commerce enterprise, and enable the e-commerce enterprise to select the cloud computing platform provided by the cloud provider according to its own wishes and enterprise needs. Cloud computing integrates a computer cluster into a virtual resource pool. All information on the e-commerce website, including the enterprise itself and users, is stored in the virtual resource pool. Specific data management is implemented by cloud computing platforms and enterprises, which means you need to choose the right system software and data platform for you. All other content has cloud computing man- agement capabilities, which greatly reduces the company's investment in data management and reduces business costs. At present, large, medium, and small e-commerce enterprises at all levels are equipped with a large number of computers and network equipment, but with the upgrade of the machine, enterprises must spend a lot of money to buy new PCs. As a result, the computer before the enterprise was eliminated. But, with cloud computing, companies do not have to give up these computers that should be eliminated, which can greatly reduce hardware investment costs. Since the user only needs to have a terminal device that can be connected to the network, the terminal device can be connected to the cloud computing platform, and the cloud computing issues performance of the terminal device that does not care about the user. Cloud computing can build a virtualized data storage center for users. It has real-world computing power. It integrates all the hardware and software functions distributed across a large number of different computers into a virtual resource pool that connects users over the network. Go to the resource pool and get the information you need from the resource pool. Cloud computing has provided many basic applications, such as office software and email systems. These applications are cheap, and some are free. And, at the other end of the cloud, there is a very professional IT team that can manage hardware and update and upgrade software for users, so users do not have to worry about whether the application is up to date. The cost savings histogram of cloud computing in different aspects is shown in Figure 5. It can be seen that in almost all aspects, the cost of cloud computing is almost more capital saving than traditional business data processing.

5.2. Data Security Advantages of E-Commerce under Cloud Computing. The cloud computing data management platform is responsible for saving data on e-commerce websites, including data backup, system maintenance, data security, 


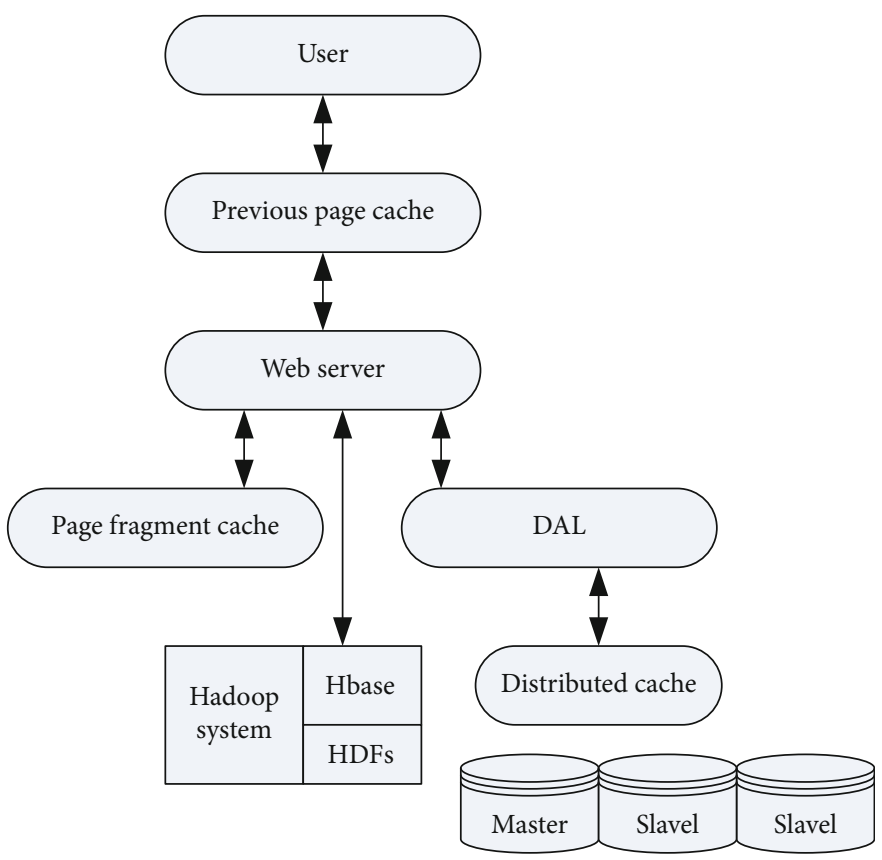

FIGURE 4: E-commerce data management model.

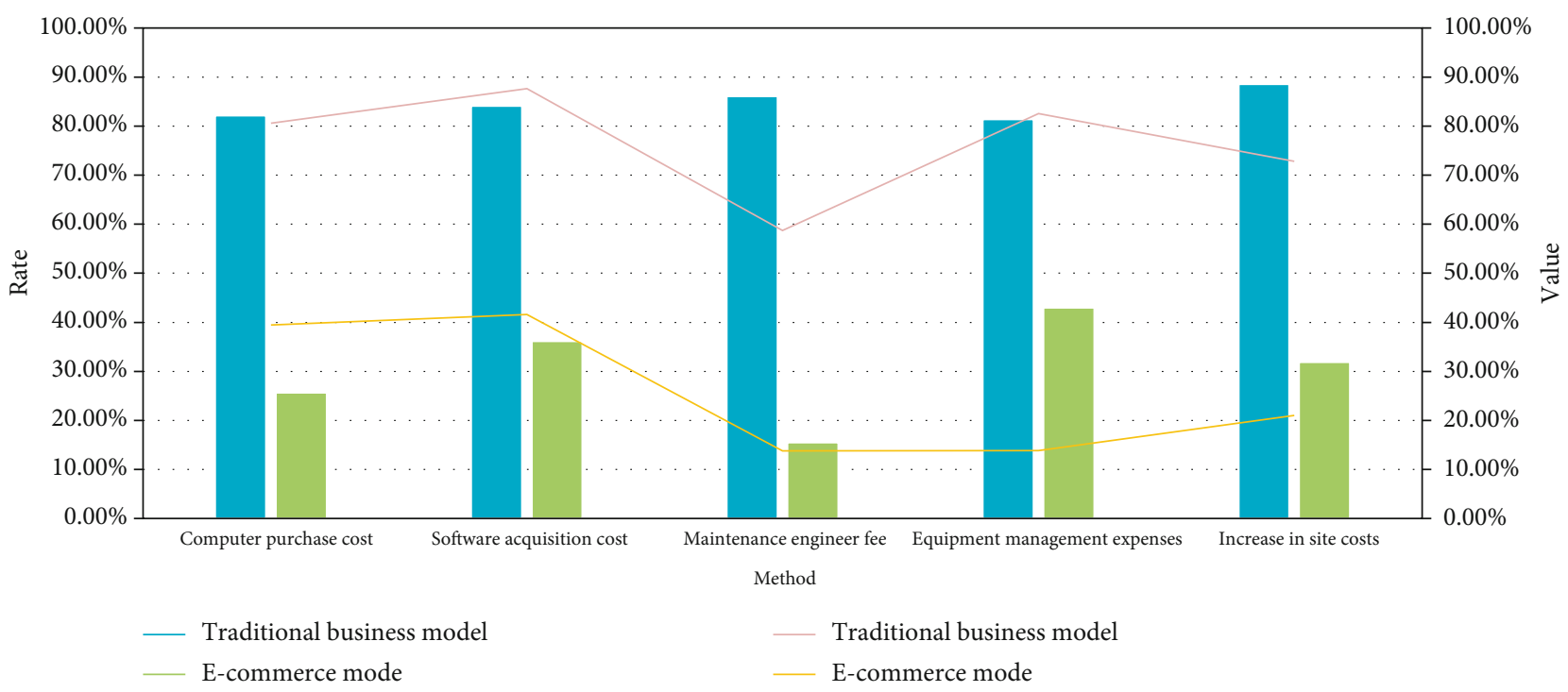

Figure 5: E-commerce cost advantages in different aspects.

and platform system upgrade. The cloud computing data management platform will ensure the security of these data, equipped with the most powerful computer administrator. And the most secure data management technology ensures the security of e-commerce enterprise data. The main task of the cloud computing data management platform is to manage the user's storage information, access information, basic information, upgrade the platform system, and virus protection, so that the entire data management platform runs normally. The user's computer, $U$ disk, etc. are particularly susceptible to poisoning, which causes a lot of trouble. A large amount of transaction information on the ecommerce website will be lost, and data related to the com- pany's life and death may be destroyed. Cloud computing can provide a secure data storage center for enterprise ecommerce sites. Cloud computing storage technology stores enterprise data in a unified cloud data management platform, and cloud computing service providers are responsible for the security of data storage. Therefore, using cloud computing data management technology to build e-commerce websites, e-commerce companies do not have to worry about data damage caused by virus damage, hacking, and computer hardware problems, which greatly enhances data security. Ecommerce sites no longer need to worry about data loss caused by viruses and hackers and hardware damage. Moreover, the emergence of these problems will increase the 

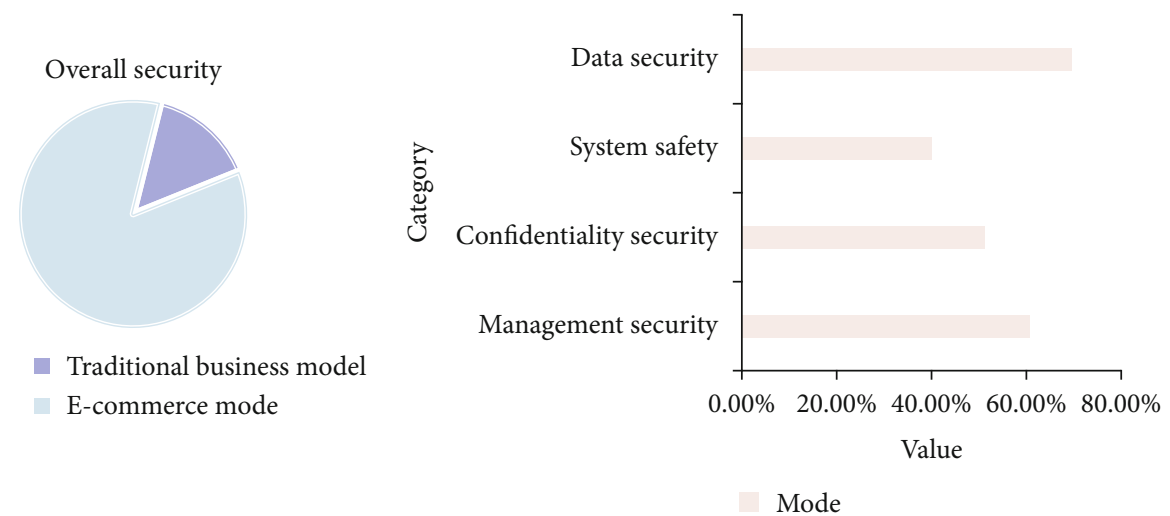

FIGURE 6: E-commerce security comparison.

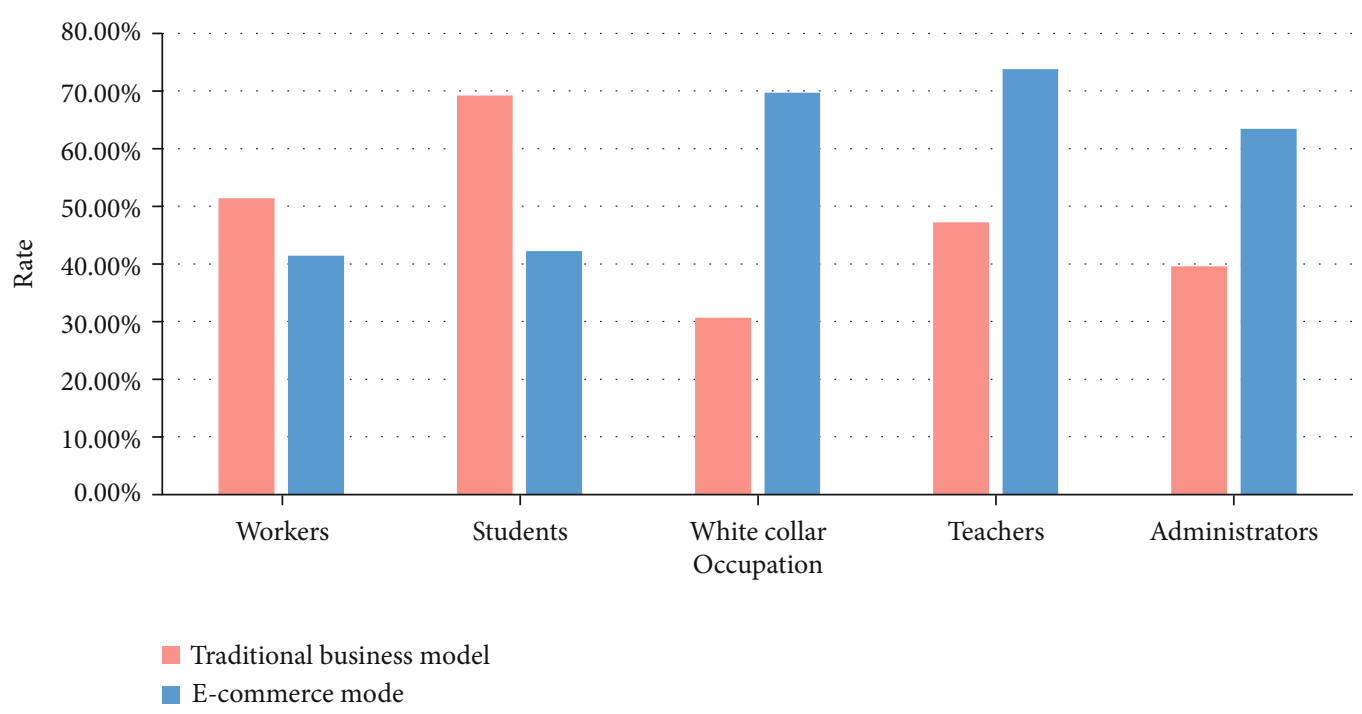

FIgURE 7: Satisfaction of different people in the information sharing advantage of e-commerce.

capital investment in e-commerce enterprise data management operations. To ensure the security of product information on the site, companies must upgrade existing systems or adopt new data management technologies, but the number of e-commerce users is increasing. It also brings a lot of data, and the cost of the business will increase. With cloud computing, these issues have been resolved. It can be seen from the above that the cloud computing data management technology for e-commerce data management can ensure the security and reliability of user data. E-commerce companies and users do not have to worry about their information being leaked or destroyed because information is the most important resource for the business. Only when the information is protected can the company carry out its activities smoothly without having to concentrate. Focusing on the secure storage of data, it can be said that cloud computing storage technology solves the worries of e-commerce enterprises. In order to prove the security advantages of e-commerce, here is a comparison of the e-commerce model and the traditional e-commerce model in this paper. Figure 6 shows the comparative analysis of the security advantages of e-commerce and traditional commerce.
5.3. Information Sharing Advantages of E-Commerce under Cloud Computing. The construction of cloud computing data management platform can enable e-commerce enterprises to share information resources to a large extent. Due to the different geographical distributions, the processing time and content of information resources of different e-commerce enterprises are different. Some enterprises cannot quickly obtain the information on the website for various reasons, which leads to the closure of enterprise information and even affects the development of the enterprise. With the cloud computing data management platform, enterprises can synchronize the business activity information of the enterprise, the resources of the enterprise, and the resources of other enterprises on the platform, which is from the external aspect. As far as the internal enterprise is concerned, it is possible to share information of the same enterprise in different places and at different times. Some enterprises have business all over the country. If the information of each branch of the enterprise cannot be communicated with each other in time, the information flow of the whole enterprise will be poor, which will affect the business activities of the enterprise. For example, a company forms an information chain from 


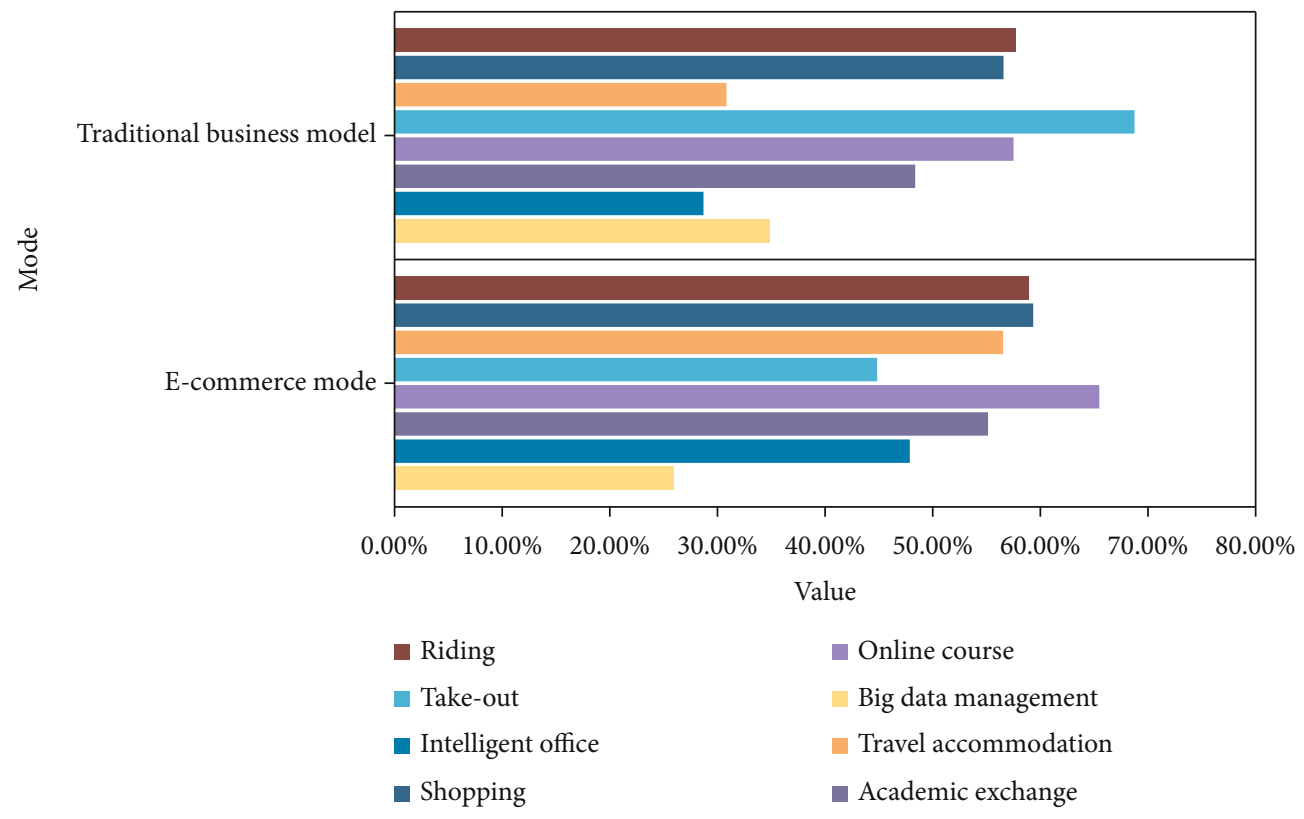

FIgURE 8: E-commerce convenience in life.

the development, production, sale, after-sales, price, market demand, logistics, etc. of the goods. In the overall market environment, not only does the company better track and understand the goods but also makes it different. The exchange and intercommunication between enterprises in the information, the sharing of information in the true sense, breaking the limits of the region and time is one advantage. At present, China's major e-commerce websites have built a large amount of commodity data. The use of cloud computing in e-commerce can share product information in the cloud and truly achieve interoperability of network resources. All e-commerce websites or business executives are able to create network resources with the powerful interoperability of computers. Cloud computing has a strong expansion, and all the data resources contained in all e-commerce websites are included in the cloud computing platform, which can greatly reduce the investment in cost and time of an ecommerce website and truly realize resource sharing. Figure 7 shows the statistics of different people's information sharing advantages in e-commerce. This survey has a total of 254 people in five categories and gives their comparison of traditional business and e-commerce advantages.

5.4. Convenient Advantage. All the data information of the ecommerce enterprise is stored on the cloud computing data management platform, and the manual management is removed, so that the user can more conveniently obtain the information he needs in any way anytime, anywhere. Since the cloud computing data management platform itself has the advantage of being efficient and fast, users will not encounter any resistance when accessing and can quickly access the platform. The customer accesses the website, processes the information, and accepts the service by connecting to the Internet, using a terminal device such as a computer, and the process is very fast and convenient. The mobile transaction is based on the wireless mobile communication network technology and related communication equipment, etc. and is obtained from the transaction of the e-commerce activity. It is not limited by time and place and can be traded as long as the terminal device can access the Internet. The emergence of cloud computing has brought greater convenience to e-commerce activities, users can conduct transactions and inquiries without restrictions, and all information about products is well known. When users want to conduct commodity transactions, they can use mobile devices to query all the information they need on the e-commerce website. E-commerce enterprise staff can even bring merchandise transactions to any place, as long as there is a computer with Internet access. Because their data is stored in the cloud, users can use this data at any time. Figure 8 shows that ecommerce is a convenience to people's lives. E-commerce has brought a lot of convenience to our lives. As you can see from Figure 8, travel expenses and online courses provide little convenience for our lives. But, in general, e-commerce has brought great convenience to people's daily lives.

In Figure 8, it can be seen that by comparing traditional business and e-commerce, e-commerce has brought a lot of convenience to people in the current social life, which also proves that the current social e-commerce has become an indispensable form of existence in people's lives. In general, e-commerce is superior to traditional business forms in the above seven aspects.

\section{Conclusions}

Cloud computing is a new form of business model and business. The advanced technology it brings can fully promote the development of future data management technology, and it also represents its development direction. As far as the development of cloud computing is concerned, it has 
strong development potential, which can reduce the time required for e-commerce enterprises to manage data, provide more convenient services for enterprises, solve problems faster, and operate more easily. More importantly, it reduces the cost of the entire operation of e-commerce data management, greatly reducing costs. As far as the development of cloud computing is concerned, cloud computing brings an opportunity for data management of e-commerce enterprises and enhances the ability of e-commerce data management from the technical level, making e-commerce enter a new stage of development. In this paper, the e-commerce data management model is mainly used as the main research object. This proves that e-commerce has great advantages in future development, and it also proves that e-commerce as a new business model will play a decisive role in future development.

\section{Data Availability}

No data were used to support this study.

\section{Conflicts of Interest}

The authors declare that they have no conflicts of interest.

\section{Acknowledgments}

The work was supported in part by Gaoyuan Discipline of Shanghai-Environmental Science and Engineering (Resource Recycling Science and Engineering), Discipline of Management Science and Engineering of Shanghai Polytechnic University (Grant No. XXKPY1606).

\section{References}

[1] F. Arnold, I. Cardenas, K. Sörensen, and W. Dewulf, "Simulation of B2C e-commerce distribution in Antwerp using cargo bikes and delivery points," European Transport Research Review, vol. 10, no. 1, 2018.

[2] H. Zhang, C. Beltran-Royo, B. Wang, and Z. Zhang, "Twophase semi-Lagrangian relaxation for solving the uncapacitated distribution centers location problem for B2C E-commerce," Computational Optimization and Applications, vol. 72, no. 3, pp. 827-848, 2019.

[3] W. Lin, A. Xu, Q. Zheng, L. Ke, and J. Lin, "Influence of customer perceived value on the online shopping intention of aquatic products under B2C E-commerce," Journal of Discrete Mathematical Sciences and Cryptography, vol. 21, no. 6, pp. 1189-1192, 2018.

[4] S. X. Xu and G. Q. Huang, "Efficient multi-attribute multi-unit auctions for B2B E-commerce logistics," Production \& Operations Management, vol. 26, no. 2, pp. 292-304, 2017.

[5] F. M. Yang, A. Y. Wang, J. Wu, and L. Tang, "Designing credit supervision mechanism in C2B2C e-commerce based on game theory," Systems Engineering-Theory \& Practice, vol. 37, no. 8, pp. 2102-2110, 2017.

[6] Y. Al-Dhuraibi, F. Paraiso, N. Djarallah, and P. Merle, "Elasticity in cloud computing: state of the art and research challenges," IEEE Transactions on Services Computing, vol. 11, no. 2, pp. 430-447, 2018.
[7] S. Sagnika, S. Bilgaiyan, and B. S. Mishra, "Workflow scheduling in cloud computing environment using bat algorithm," International Journal of Computer Applications, vol. 89, no. 2, pp. 11-18, 2018.

[8] M. Zhang, Y. Yao, Y. Jiang, B. Li, and C. Tang, "Accountable mobile E-commerce scheme in intelligent cloud system transactions," Journal of Ambient Intelligence \& Humanized Computing, vol. 9, no. 6, pp. 1889-1899, 2018.

[9] R. Gubela, A. Bequé, S. Lessmann, and F. Gebert, "Conversion uplift in E-commerce: a systematic benchmark of modeling strategies," International Journal of Information Technology \& Decision Making, vol. 18, no. 3, pp. 747-791, 2019.

[10] J. Xue and S. Jarvis, "Mining association rules for admission control and service differentiation in e-commerce applications," Wiley Interdisciplinary Reviews Data Mining \& Knowledge Discovery, vol. 8, no. 3, article e1241, 2018.

[11] H. J. M. Ter Brake, J. Flokstra, E. P. Houwman et al., "Design and construction of a 19-channel DC-SQUID neurokagnetoneter," Physica B: Condensed Matter, vol. 165-166, Part 1, pp. 95-96, 1990. 